\title{
Neurocognitive and Academic Outcomes at Age 10 Years of Extremely Preterm Newborns
}

Robert M. Joseph, PhD, a Thomas M. 0'Shea, MD, MPH, ${ }^{b}$ Elizabeth N. Allred, MS, , d, Tim Heeren, PhD, ${ }^{e}$ Deborah Hirtz, MD, ${ }^{f}$ Hernan Jara, PhD, ${ }^{, f}$ Alan Leviton, MD, ${ }^{c, d}$ Karl C.K. Kuban, MD, SMEpi, ${ }^{\text {h }}$ for the ELGAN Study Investigators

BACKGROUND AND OBJECTIVE: Despite reductions in mortality and morbidity among children born extremely preterm, they remain at high risk of neurocognitive deficits, with up to $40 \%$ having significant cognitive deficits at school age. We assessed the rate of neurocognitive impairment in a contemporary US cohort of 873 children aged 10 years who were born $<28$ weeks' gestation.

METHODS: The families of 889 of 966 (92\%) children enrolled from 2002 to 2004 at 14 sites in 5 states returned at age 10 years for a comprehensive assessment of IQ, language, attention, executive function, processing speed, visual perception, visual-motor function, and academic achievement.

RESULTS: A total of 873 children were assessed with well-validated tests of cognitive and academic function. Distributions of test scores were consistently and markedly shifted below normative expectation, with one-third to two-thirds of children performing $>1 \mathrm{SD}$ below age expectation. The most extreme downward shifts were on measures of executive control and processing speed. Multivariate analyses, adjusted for socioeconomic status, growth restriction, and other potential confounders, revealed that the risk of poor outcome was highest at the lowest gestational age across all 18 measures.

concLusions: More than half of our extremely preterm cohort exhibited moderate or severe neurocognitive deficits at age 10 years, with the most extensive impairments found among those born at the lowest gestational age. Children born extremely preterm continue to be at significant risk of persistent impairments in neurocognitive function and academic achievement, underscoring the need for monitoring and remediating such outcomes beginning in early childhood.

Departments of ${ }^{a}$ Anatomy and Neurobiology and ${ }^{g}$ Radiology, School of Medicine, and ${ }^{e}$ Department of Biostatistics, School of Public Health, Boston University, Boston, Massachusetts; ${ }^{b}$ Department of Pediatrics, University of North Carolina, Chapel Hill, North Carolina; ' Department of Neurology, Harvard Medical School, Boston, Massachusetts; ${ }^{d}$ Neuroepidemiology Unit, Department of Neurology, Boston Children's Hospital, Boston, Massachusetts; ${ }^{f}$ National Institute of Neurologic Disorders and Stroke, Bethesda, Maryland; and ${ }^{h}$ Department of Pediatrics, Boston Medical Center, Boston, Massachusetts

Dr Joseph conceptualized and designed the study, interpreted the data, drafted the initial manuscript, and revised the manuscript; Drs 0'Shea, Leviton, Kuban, Hirtz, and Jara contributed to the conceptualization and design of the study and interpretation of the data and reviewed and revised the manuscript; Ms Allred and Dr Heeren contributed to the conceptualization and design of the study, conducted statistical analyses, contributed to the interpretation of the data, and reviewed and revised the manuscript; and all authors approved the final manuscript as submitted.

DOI: $10.1542 /$ peds.2015-4343

Accepted for publication Jan 15, 2016
WHAT'S KNOWN ON THIS SUBJECT: Compared with children born near term, those born extremely preterm are at significantly increased risk of deficits in neurocognitive function and academic achievement at school age and beyond, but advances in neonatal care may have reduced this risk.

WHAT THIS STUDY ADDS: School-aged children born extremely preterm in the past decade remain at high risk of poor neurocognitive and academic outcomes, and the risk of poorer outcomes is associated with lower gestational age.

To cite: Joseph RM, O'Shea TM, Allred EN, et al. Neurocognitive and Academic Outcomes at Age 10 Years of Extremely Preterm Newborns. Pediatrics. 2016;137(4):e20154343 
Extremely preterm children are at heightened risk of deficits in IQ, ${ }^{1-6}$ attention, 7,8 executive function, ${ }^{4,6,9-14}$ processing speed, ${ }^{15-17}$ visual perception, 6,14 and visual-motor function. ${ }^{6,14}$ Neurocognitive deficits are accompanied by delays in academic attainment. 6,18-20 These deficits vary in their severity according to the degree of prematurity, whether measured by birth weight ${ }^{6}$ or gestational age (GA). ${ }^{1,21}$ However, effects of prematurity on neurocognitive outcomes have not been found consistently, $^{22}$ possibly because of small samples with restricted ranges of $\mathrm{GA}^{22}$ and inadequate adjustment for confounding factors, such as intrauterine growth restriction. ${ }^{4}$ 23 Knowing whether lower GA places extremely preterm children at heightened risk of enduring neurocognitive impairment has important implications regarding the need to prioritize development of novel preventive and therapeutic strategies that minimize the impact of extreme immaturity. ${ }^{24}$

We assessed neurocognitive and academic ability in a US cohort of 889 children aged 10 years who were born at 23 to 27 weeks' GA from 2002 to 2004 . In addition, we examined the effect of weeks of gestation at birth on the risk of neurocognitive and academic outcomes among this cohort of children. Our large sample size afforded us the power to detect GA gradient effects on neurocognitive outcomes, even within the narrow range of 23 to 27 weeks of GA.

\section{METHODS}

\section{Participants}

The Extremely Low Gestational Age Newborn (ELGAN) Study is an observational study of the risk of structural and functional neurologic disorders in extremely preterm infants. All procedures for this study were approved by the institutional review boards of all participating institutions.

During the years 2002 to 2004, women delivering before 28 weeks' gestation in 11 cities in 5 states were asked to enroll in the study. A total of 1506 infants, born to 1249 mothers, were enrolled and 1198 survived to age 10 years. We actively recruited 966 children who had measurements of inflammation-related proteins in blood obtained during the first postnatal weeks. The families of 889 (92\%) children agreed to participate. Eleven children did not accompany the parent or caregiver during the follow-up visit, and 5 children did not cooperate with the child assessment, leaving a final sample of 873 children. Supplemental Table 3 compares the maternal and newborn characteristics of the 873 children who were assessed and the 93 children who were not assessed from among the 966 children eligible for study participation at age 10 years. Study participants who were eligible but who did not return were more likely to have indicators of social disadvantage, such as eligibility for public assistance. These indicators are associated with lower scores on cognitive tests. The bias from lost-tofollow-up children would be expected to result in overestimation of cognitive abilities in the cohort. Given the low frequency of children who were lost to follow-up, the magnitude of this bias very likely was small.

\section{Maternal and Newborn Characteristics}

Maternal age, education, marital status, eligibility for governmentprovided medical care insurance (eg, Medicaid), and racial and ethnic identity were self-reported. To approximate the heritable component of child IQ, maternal IQ was assessed with the Kaufman Brief Intelligence Test-2 (KBIT-2) ${ }^{25}$ Nonverbal subscale at the 10 -year visit.
Newborns were selected on the basis of GA and not birth weight. Newborn characteristics (GA, birth weight, and growth restriction), neonatal brain injuries (echolucent lesions of cerebral white matter, ventriculomegaly), and neonatal medical characteristics (necrotizing enterocolitis requiring surgery, prethreshold retinopathy of prematurity, and bronchopulmonary dysplasia) were defined according to standard procedures. $^{26}$

\section{Procedures at Age 10 Years}

Child measures were selected to provide the most comprehensive assessment of neurocognitive and academic function obtainable in a single testing session to maximize participation and data collection. While the child was being tested, the parent or caregiver completed questionnaires regarding the child's medical and neurologic status and behavioral outcomes.

\section{Sensorimotor Status at Age 10 Years}

Severe gross motor dysfunction was defined as level 5 (ie, no selfmobility) on the Gross Motor Function Classification System. ${ }^{27}$ A child was considered to have severe visual impairment if the parent reported uncorrectable functional blindness in both eyes. No participant had a significant, uncorrected hearing impairment.

\section{Neurocognitive and Academic Ability} at Age 10 Years

Neurocognitive and academic achievement assessments were based on well-validated tests with recently standardized scores allowing comparison with US population norms. Each subtest is described in detail in Supplemental Table 4.

\section{General Cognitive Ability}

General cognitive ability (or IQ) was assessed with the SchoolAge Differential Ability Scales-II (DAS-II) ${ }^{28}$ Verbal and Nonverbal Reasoning scales. The DAS-II has 
several advantages for characterizing the wide range of IQs in a preterm sample, including more sensitive basal items than other IQ scales and extended standard scores (down to 31$).{ }^{29}$ In addition, the DAS-II Nonverbal Reasoning subtests require minimal visual-spatial processing and fine motor dexterity, allowing a more accurate estimate of nonverbal IQ in preterm children.

\section{Language Ability}

Expressive and receptive language skills were evaluated with the Oral and Written Language Scales, ${ }^{30}$ which assess semantic, morphologic, syntactic, and pragmatic production and comprehension of elaborated sentences.

\section{Executive Function}

Attention and executive functions were assessed with the DAS-II and the Developmental NEuroPSYchological Assessment-II (NEPSY-II). ${ }^{31}$ DAS-II Recall of Digits Backward and Recall of Sequential Order measured verbal working memory. The NEPSY-II Auditory Attention and Auditory Response Set evaluated auditory attention, set switching, and inhibition. NEPSY-II Inhibition Inhibition and Inhibition Switching assessed simple inhibition and inhibition in the context of set shifting, respectively. The NEPSY-II Animal Sorting measured concept generation and mental flexibility.

\section{Speed of Processing}

Speed of processing was assessed with NEPSY-II Inhibition Naming, a baseline measure of processing speed with no inhibitory component.

\section{Visual Perception}

Visual perception was assessed with NEPSY-II Arrows, which measures perception of line orientation, and Geometric Puzzles, a measure of mental rotation of complex visualspatial figures.

\section{Visual-Motor Function}

Visual fine motor function was measured with NEPSY-II Visuomotor Precision.

\section{Academic Achievement}

The Wechsler Individual Achievement Test-III (WIATIII) ${ }^{32}$ Word Reading, Pseudoword Decoding, and Spelling subtests were used to assess proficiency in word recognition, decoding, and spelling, respectively. WIAT-III Numeric Operations was used to assess mathrelated computational skills.

\section{Data Analyses}

We evaluated 2 null hypotheses: first, the distributions of neurocognitive and academic test scores among ELGAN participants do not differ from normative expectation; second, when controlling for the effects of confounding variables, lower GA is not associated with increased risk of neurocognitive and academic impairment. To determine if the performance of ELGAN participants on our measures differed from normative expectation, we converted children's scores to $z$ scores using the normative means and SDs for each subtest. On the basis of a standard normal distribution, 2.3\% of ELGAN children would be expected to have $z$ scores $\leq-2,13.7 \%$ to have $z$ scores $>$ -2 and $\leq-1,68.2 \%$ to have $z$ scores $>-1$ and $\leq 1$, and $15.8 \%$ to have $z$ scores $>1$. We used $\chi^{2}$ goodnessof-fit tests to evaluate the extent to which the distribution of scores in the ELGAN cohort differed from normative expectation.

To examine GA effects on neurocognitive and academic outcomes, we used multinomial logistic regression to compare children born at 23 to 24 weeks and 25 to 26 weeks' GA with those born at 27 weeks' GA. We calculated the likelihood of having a test score $\geq 2$ SDs or between 1 and 2 SDs below the normative mean, adjusting for maternal IQ (KBIT-2 z score $\leq-1$ ), maternal education $\leq 12$ years, black race, and birth weight $z$ score $<-1$. In addition, given evidence from previous studies ${ }^{1,6}$ and from the present cohort (Kuban KC, MD, Joseph RM, PhD, O'Shea TM, MD, unpublished data) that the rate of neurocognitive deficits is higher among boys than girls, we also adjusted for male gender.

\section{RESULTS}

\section{Sample Description}

Of the 873 children in this sample, $21 \%(n=180)$ were born at 23 or 24 weeks' GA, 45\% ( $n=395)$ were born at 25 or 26 weeks' GA, and $34 \%(n=298)$ were born at 27 weeks' GA (Table 1). Demographic characteristics associated with delivery before 27 weeks' gestation were maternal age $<21$ years, maternal education $\leq 12$ years, and mother's identification as black. Boys were more likely than girls to be born in the lowest GA stratum. Severely growth-restricted infants (ie, birth weight $z$ score $<-2$ ) were least likely to be in the lowest GA stratum.

Of the 873 participants, 17 (1.9\%) had severe motor impairment (Gross Motor Function Classification System $=5), 7(0.8 \%)$ had functional blindness, and $2(0.2 \%)$ had both severe motor impairment and functional blindness. Participants not able to obtain a basal score on any given test because of severe cognitive impairment were assigned a floor score for that test. Of the 26 children with severe motor or visual impairment, 17 did not achieve basal scores on any test, and 2 obtained basal scores on some but not all measures. Of children without severe motor or visual impairment, 12 did not achieve basal scores on any test, and 9 achieved basal scores on only some tests. In summary, a total of 29 children were assigned floor scores on all tests, and 11 were assigned floor scores on some tests. 
TABLE 1 Sample Characteristics by GA

\begin{tabular}{|c|c|c|c|c|}
\hline & & GA & & \\
\hline & 23-24 Weeks & 25-26 Weeks & 27 Weeks & $n$ \\
\hline \multicolumn{5}{|l|}{ Maternal characteristics } \\
\hline \multicolumn{5}{|l|}{ Age, y } \\
\hline$<21$ & 25 & 47 & 28 & 113 \\
\hline $21-35$ & 21 & 46 & 34 & 585 \\
\hline$>35$ & 18 & 43 & 38 & 175 \\
\hline \multicolumn{5}{|l|}{ Education } \\
\hline$\leq 12$ years (high school) & 22 & 48 & 30 & 347 \\
\hline$>12$ and $<16$ years & 27 & 36 & 37 & 198 \\
\hline $\begin{array}{l}\geq 16 \text { years (college or } \\
\text { higher) }\end{array}$ & 16 & 46 & 38 & 303 \\
\hline \multicolumn{5}{|l|}{ Maternal IQ (z Score) } \\
\hline$\leq-2$ & 12 & 61 & 27 & 33 \\
\hline$>-2$ and $\leq-1$ & 21 & 52 & 27 & 62 \\
\hline$>-1$ and $\leq 1$ & 21 & 44 & 35 & 603 \\
\hline \multicolumn{5}{|l|}{ Single marital status } \\
\hline Yes & 21 & 45 & 34 & 348 \\
\hline No & 20 & 45 & 34 & 525 \\
\hline \multicolumn{5}{|l|}{ Public insurance } \\
\hline Yes & 21 & 47 & 32 & 301 \\
\hline No & 21 & 44 & 36 & 559 \\
\hline \multicolumn{5}{|l|}{ Racial identity } \\
\hline White & 21 & 43 & 37 & 542 \\
\hline Black & 22 & 51 & 27 & 226 \\
\hline Other & 17 & 44 & 39 & 95 \\
\hline \multicolumn{5}{|l|}{ Hispanic } \\
\hline Yes & 23 & 40 & 37 & 86 \\
\hline No & 20 & 46 & 34 & 784 \\
\hline \multicolumn{5}{|l|}{ Newborn characteristics } \\
\hline \multicolumn{5}{|l|}{ Gender } \\
\hline Male & 23 & 45 & 32 & 445 \\
\hline Female & 18 & 46 & 36 & 428 \\
\hline \multicolumn{5}{|l|}{ Birth weight, g } \\
\hline$\leq 750$ & 50 & 37 & 13 & 323 \\
\hline $751-1000$ & 5 & 61 & 33 & 378 \\
\hline$>1000$ & 0 & 24 & 76 & 172 \\
\hline \multicolumn{5}{|l|}{ Birth weight $z$ score } \\
\hline$<-2$ & 4 & 69 & 27 & 51 \\
\hline$\geq-2$ and $<-1$ & 18 & 45 & 37 & 116 \\
\hline$\geq-1$ & 22 & 44 & 34 & 706 \\
\hline \multicolumn{5}{|l|}{ Postnatal characteristics } \\
\hline \multicolumn{5}{|l|}{ Echolucent lesion } \\
\hline Yes & 29 & 42 & 29 & 55 \\
\hline No & 20 & 45 & 34 & 818 \\
\hline \multicolumn{5}{|l|}{ Ventriculomegaly } \\
\hline Yes & 30 & 46 & 24 & 92 \\
\hline No & 19 & 45 & 35 & 781 \\
\hline \multicolumn{5}{|l|}{$\begin{array}{l}\text { Necrotizing enterocolitis (Bell } \\
\text { stage } 3 b \text { ) }\end{array}$} \\
\hline Yes & 33 & 57 & 10 & 30 \\
\hline No & 20 & 45 & 35 & 843 \\
\hline \multicolumn{5}{|l|}{$\begin{array}{l}\text { Retinopathy of prematurity } \\
\text { pre-threshold) }\end{array}$} \\
\hline Yes & 44 & 49 & 7 & 113 \\
\hline No & 17 & 45 & 37 & 747 \\
\hline \multicolumn{5}{|l|}{$\begin{array}{l}\text { Bronchopulmonary dysplasia } \\
\text { (oxygen at } 36 \text { weeks) }\end{array}$} \\
\hline Yes & 32 & 46 & 22 & 452 \\
\hline No & 9 & 44 & 47 & 414 \\
\hline Maximum column $N$ & 180 & 395 & 298 & 873 \\
\hline
\end{tabular}

Data are presented as percentages unless otherwise indicated. Maximum $N=873$.
Distribution of Neurocognitive and Academic Outcomes

In the ELGAN cohort, distributions of test scores were consistently and markedly shifted below normative expectations (Table 2). On IQ (DAS-II), language (Oral and Written Language Scales), and neuropsychological (NEPSY-II) measures, $15 \%$ to $34 \%$ of ELGAN test scores were $\geq 2$ SDs below the population mean, compared with the normative expectation of $2.3 \%$, and $18 \%$ to $39 \%$ fell between 1 and 2 SDs below the mean, compared with the normative expectation of $13.7 \%$. The downward shift in scores was most striking on the NEPSY-II executive control measures of inhibition, set maintenance, and set shifting (Auditory Response Set, Inhibition Inhibition, and Inhibition Switching), mental flexibility (Animal Sorting), and processing speed (Inhibition Naming), for which 51\% to $69 \%$ of scores were $\geq 1$ SDs below the population mean, compared with the normative expectation of $16 \%$. On WIAT-III measures of academic achievement, $13 \%$ to $17 \%$ of scores were $\geq 2$ SDs and $16 \%$ to $23 \%$ were between 1 and 2 SD units below the mean, compared with normative expectations of $2.3 \%$ and $13.7 \%$, respectively.

\section{GA-Related Effects on Neurocognitive and Academic Outcomes}

Box-and-whisker plots in Fig 1 display the distribution of $z$ scores on each measure for each GA group (Supplemental Table 5). For every measure, the distribution of scores shifted downward with decreasing GA. The stepwise pattern of lowest scores among the 23- to 24-week group, intermediate scores among the 25- to 26-week group, and highest scores among the 27-week group was seen for every test. In addition, the median scores of the 27-week group were consistently below normative expectation for 
all neurocognitive and academic achievement measures.

In multivariate analyses, adjusting for maternal education $\leq 12$ years, maternal IQ (KBIT-2 $z$ score $\leq$ $-1)$, black race, male gender, and birth weight $z$ score $<-1$, and with children born at 27 weeks' GA as the referent group, children born at 23 to 24 weeks were at significantly higher risk of scoring $\geq 2$ SDs below the normative expectation on all tests (Fig 2, Supplemental Table 6). For the 23- to 24-week group, odds ratios for increased risk of scores $\leq 2$ SDs ranged from 1.6 to 5.9 and were $>3.0$ on 16 of the 18 neurocognitive and academic measures. The most striking effects for children in the lowest GA stratum were seen on tests of nonverbal IQ, receptive language, visual perception, and visual-motor control. The 23- to 24-week GA group was also at higher risk of scoring between 1 and 2 SDs below the population mean on two-thirds of test measures. Children born at 25 to 26 weeks showed a more moderate but significantly increased risk of scoring $\geq 2$ SDs below normative expectation, with risk ratios ranging from 1.6 to 2.4 on 11 of 18 tests. The 25- to 26-week group was at significantly increased risk of scores between 1 and 2 SDs below the norm on only 2 measures, mental flexibility and visual perception.

\section{DISCUSSION}

\section{Neurocognitive and Academic Outcomes Among ELGAN Participants at School Age}

In this sample of 873 children born from 2002 to 2004 before the 28th week of gestation and assessed at age 10 years, the distributions of scores on all neurocognitive and academic tests were consistently and markedly shifted downward, significantly below normative expectation, and poorer scores were associated with lower GA at birth. From one-third to two-thirds of the sample performed

TABLE 2 Distributions of Neurocognitive Test Scores in the Total Sample Compared to the Normal Distribution

\begin{tabular}{|c|c|c|c|c|}
\hline & \multicolumn{4}{|c|}{ zScore } \\
\hline & $\leq-2$ & $\begin{array}{c}>-2 \text { and } \leq \\
-1\end{array}$ & $\begin{array}{c}>-1 \text { and } \\
\leq 1\end{array}$ & $>1$ \\
\hline Normal distribution & 2.3 & 13.7 & 68.2 & 15.8 \\
\hline \multicolumn{5}{|l|}{ General cognitive ability } \\
\hline DAS-II Verbal & 17 & 19 & 57 & 7 \\
\hline DAS-II Nonverbal Reasoning & 15 & 24 & 56 & 5 \\
\hline \multicolumn{5}{|l|}{ Language } \\
\hline OWLS Listening Comprehension & 19 & 27 & 50 & 4 \\
\hline OWLS Oral Expression & 19 & 22 & 52 & 6 \\
\hline \multicolumn{5}{|l|}{ Executive function } \\
\hline DAS-II Working Memory & 18 & 18 & 61 & 4 \\
\hline NEPSY-II Auditory Attention & 23 & 21 & 56 & 0 \\
\hline NEPSY-II Auditory Response Set & 20 & 28 & 48 & 4 \\
\hline NEPSY-II Inhibition Inhibition & 34 & 23 & 40 & 3 \\
\hline NEPSY-II Inhibition Switching & 27 & 29 & 37 & 6 \\
\hline NEPSY-II Animal Sorting & 29 & 30 & 38 & 3 \\
\hline \multicolumn{5}{|l|}{ Processing speed } \\
\hline NEPSY-II Inhibition Naming & 31 & 20 & 41 & 8 \\
\hline \multicolumn{5}{|l|}{ Visual perception } \\
\hline NEPSY-II Arrows & 26 & 22 & 46 & 6 \\
\hline NEPSY-II Geometric Puzzles & 17 & 22 & 57 & 4 \\
\hline \multicolumn{5}{|l|}{ Fine motor function } \\
\hline NEPSY-II Visuomotor Precision & 21 & 35 & 38 & 7 \\
\hline \multicolumn{5}{|l|}{ Achievement } \\
\hline WIAT-III Word Reading & 14 & 16 & 57 & 13 \\
\hline WIAT-III Pseudoword Decoding & 16 & 18 & 57 & 9 \\
\hline WIAT-III Spelling & 14 & 21 & 54 & 11 \\
\hline WIAT-III Numeric Operations & 17 & 24 & 54 & 5 \\
\hline Maximum column $N$ & 180 & 395 & 298 & 873 \\
\hline
\end{tabular}

Data are presented as percentages unless otherwise indicated. Maximum $N=873$. OWLS, Oral and Written Language Scales. In $\chi^{2}$ goodness-of fit tests, distributions of scores for all measures differed significantly from the normative expectation at $\mathrm{P}<.001$.

substantially (>1 SD) below age expectation on measures of general cognitive ability, language, attention, executive control, processing speed, visual perception, fine motor ability, and academic achievement in reading and math. The frequency of moderate-to-severe deficits in general cognitive ability and academic achievement was similar to rates reported for earlier cohorts assessed at comparable ages. 1,2,6,18,33 Corresponding deficits among ELGAN participants across measures of attention, executive control, and processing speed as well as visual perception and fine motor control were also comparable to those reported for earlier cohorts. ${ }^{4,6,14}$, ${ }^{34}$ Our findings indicate that schoolaged children born extremely preterm continue to be at significant risk of a wide range of neurocognitive and academic deficits.

\section{GA and Risk of Neurocognitive Disability}

In the narrow GA range of the ELGAN sample, the frequency and extent of the downward shift in test scores at age 10 years varied with the length of gestation, with the 23- to 24-week group showing the most extreme and consistent downward shift and the 25- to 26-week group performing intermediately relative to the 27-week referent group, whose median scores were still consistently below normative expectations on all measures. GA effects were adjusted for potential confounders, including birth weight $z$ score $<-1$, male gender, maternal IQ, and socioeconomic indicators (maternal education $\leq 12$ years, 
black race). Thus, with adjustments for key confounders such as growth restriction and low socioeconomic status, our findings clearly indicate that GA and neurocognitive abilities are positively related even among extremely preterm children.

Accordingly, we propose that GA conveys unique information about developmentally regulated processes that, when disrupted, put the very preterm neonate at heightened risk of disordered brain maturation, resulting in enduring neurocognitive deficits. ${ }^{35}$ For example, very preterm newborns are less able than infants closer to term to synthesize growth factors in the amounts needed for normal development. ${ }^{36}$ Brain developmental processes underway at midgestation and after, including neuronal migration, oligogenesis, axonal and synapse formation, and myelination, ${ }^{37-40}$ appear to be especially vulnerable to these growth factor deficiencies. ${ }^{41}$ In addition, the reduced quantities of these growth promoters are also suboptimal for protecting against adversity, ${ }^{42}$ including a host of potentially harmful exposures before, during, and after delivery, with many differing qualitatively (as well as quantitatively) from those experienced by term infants. ${ }^{41}$ Thus, the lower GA at birth, the greater the immaturity and vulnerability of the neonate's central nervous system and the higher the risk of brain damage and neurocognitive impairment.

Our finding of a gradient of neurocognitive impairment associated with GA among ELGAN participants at age 10 is consistent with neuroimaging findings that revealed widespread abnormalities in brain development and organization in children born very preterm. Compared with term-born neonates, preterm neonates at term-equivalent age show volume reductions in subcortical gray matter nuclei, including the thalamus, hippocampus, and striatum, ${ }^{43,44}$ and reduced white
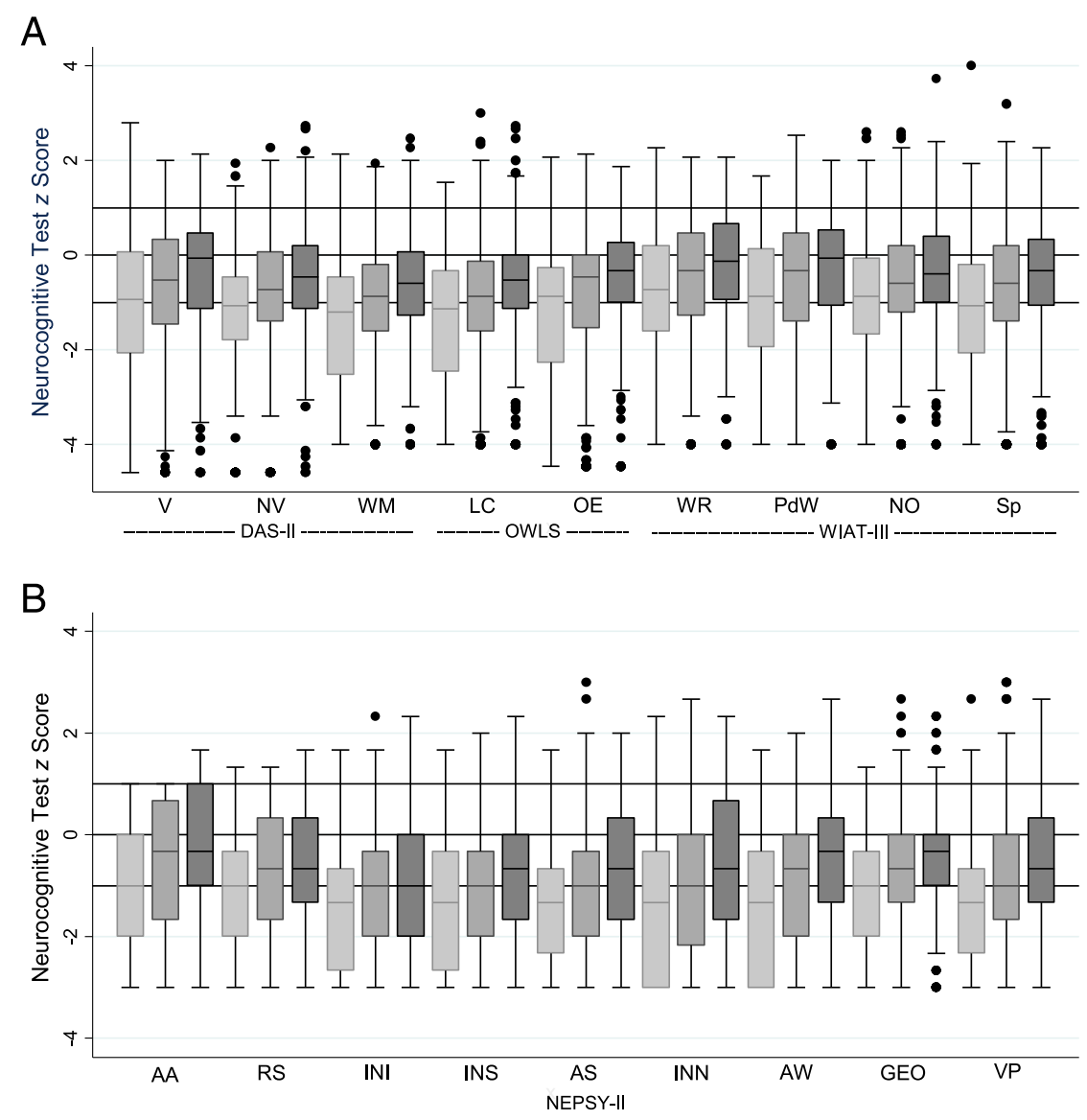

FIGURE 1

Box-and-whisker plots of each neurocognitive subtest by GA category. $z$ Scores according to DAS-II, OWLS, and WIAT-III (A) and NEPSY-II (B) were adjusted to population norms. Maximum $N=873$. Light gray bars indicate 23-24 weeks, medium gray bars indicate 25-26 weeks, and dark gray bars represent 27 weeks. The central line in the boxes indicates the median (50th centile), the top of the boxes indicates the 75th centile, and the bottom of the boxes indicates the 25th centile. Solid circles represent outliers. If ELGAN participants had the expected normal distribution of term-born children, the middle of the box would be at $z=0$ and the upper and lower ends of the box would be at $z=$ 1 and $z=-1$, respectively. AA, Auditory Attention; AS, Animal Sorting; AW, Arrows; GE0, Geometric Puzzles; INI, Inhibition Inhibition; INN, Inhibition Naming; INS, Inhibition Switching; LC, Listening Comprehension; NO, Numeric Operations; NV, Nonverbal Reasoning; OE, Oral Expression; OWLS, Oral and Written Language Scales; PdD, Pseudoword Decoding; RS, Auditory Response Set; Sp, Spelling; WM, Working Memory; WR, Word Reading; V, Verbal.

matter connectivity in subcorticocortical and cortico-cortical networks that underlie higher cognitive function. ${ }^{43,45}$ The severity of these alterations in gray and white matter brain organization in the preterm neonate has been linked to the degree of prematurity ${ }^{44-46}$ and with poorer neurocognitive outcomes at preschool age and school age. ${ }^{44,47,48}$

\section{Strengths and Limitations}

Among the strengths of this study is the selection of children on the basis of GA, rather than birth weight. Although some view the 2 as equivalent, very low birth weight samples have an overrepresentation of growth-restricted infants whose GA might be older than most others in the cohort. ${ }^{26-28}$ Consequently, birth weight-defined samples cannot adequately assess the contribution to immaturity/vulnerability that is specifically determined by GA. Other strengths of this study include the relatively large number of children who were born at an extremely low GA and followed until age 10 years and the broad assessment 
of neurocognitive and academic function. The main limitation is our lack of a term control group, which required us to estimate neurocognitive and academic outcomes in relation to the respective test norms. The lack of a control group also prevented us from identifying more precisely areas of specific neurocognitive impairment. Thus, although we observed relatively pronounced deficits in executive control and processing speed, which is consistent with the neuroimaging evidence of diffuse and widespread perturbations in brain development and organization in extremely preterm children, we could not rule out that these findings were to some extent artifacts of the psychometrics (including the norming) of the test, in this case the NEPSY-II, which yielded these results. Accordingly, we cannot make strong claims about differential impairment across our measures.

\section{Conclusions and Implications}

More than half of our extremely preterm cohort exhibited moderateto-severe neurocognitive deficits at age 10 years, with the most severe impairment found among those born at a lower GA. Survival rates over the past 2 decades have increased primarily among those children born most premature, at 23 to 24 weeks' $\mathrm{GA},{ }^{24}$ whose immaturity puts them at highest risk. Increased survival of these particularly high-risk infants may offset an improvement in neurocognitive outcomes among those born more mature such that no overall improvement was found in our cohort relative to earlierborn cohorts. ${ }^{34}$ Our finding of a steep GA gradient in neurocognitive outcomes is consistent with this possibility. Other factors may also contribute to our findings, such as the socioeconomic status composition of our sample compared with others.

For many or even most children, neurocognitive deficits identified at age 10 years are likely to persist
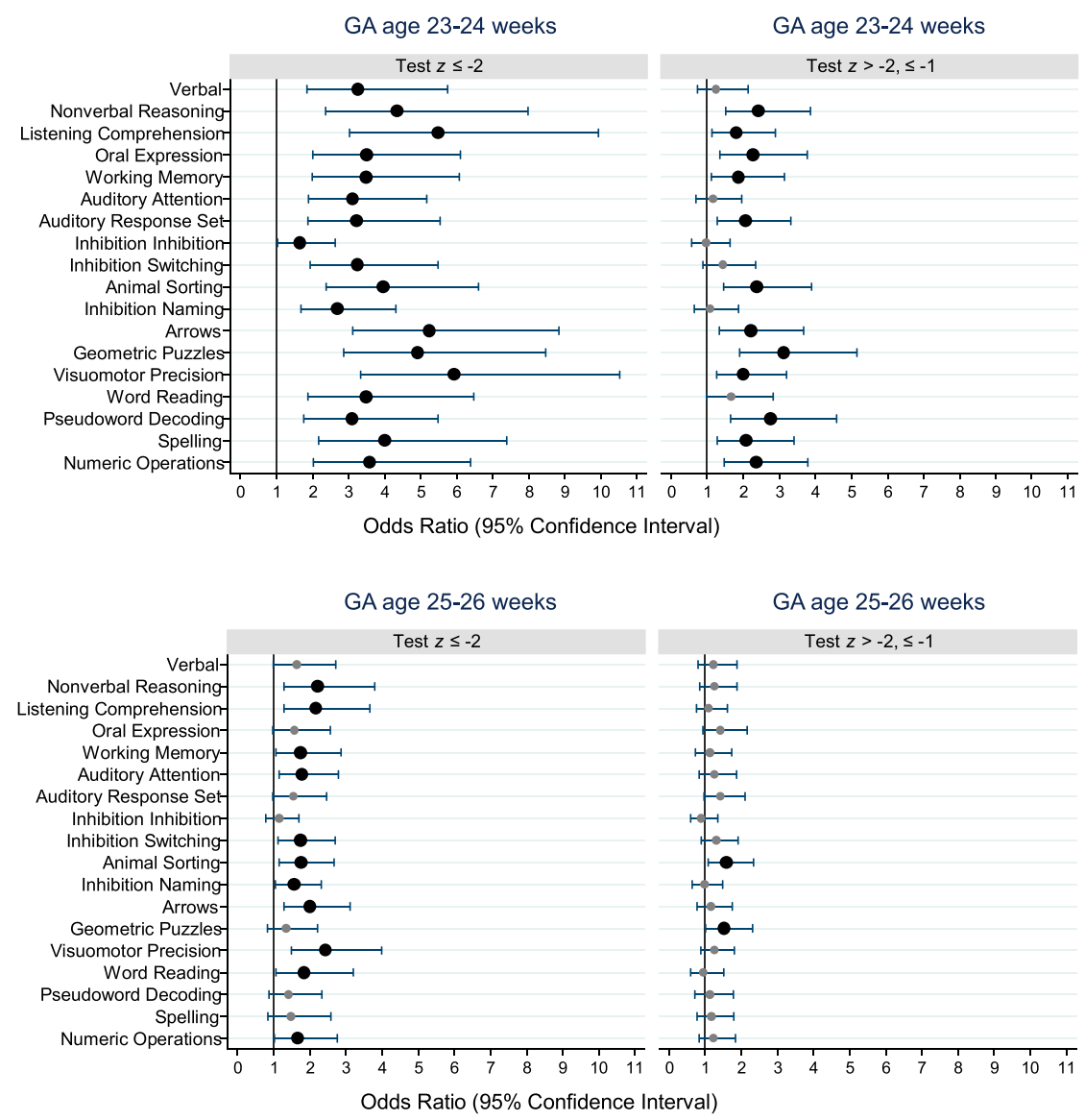

FIGURE 2

Forest plots of odds ratios and 95\% confidence intervals of $z$ scores $\leq-2$ (left panels) and $z$ scores $>-2$ but $\leq-1$ (right panels) for each DAS-II, OWLS, NEPSY-II, and WIAT-III assessment at age 10 years associated with a GA of 23-24 weeks (top panel) or a GA of 25-26 weeks (bottom panel). All odds ratios were adjusted for maternal IQ (KBIT-2 $z$ score $\leq-1$ ), maternal education $\leq 12$ years, black race, male gender, and birth weight $z$ score $<-1$. Large black dots indicate odds ratios that were significantly $>1.0$. Maximum $N=873$. OWLS, Oral and Written Language Scales.

through adolescence and into adulthood ${ }^{3,4}$ and can be expected to have a negative impact on academic attainment and later vocational function. Our findings underscore the need for routine assessment of neurocognitive function in all children born extremely preterm. Moreover, our findings highlight the need for the development of medical interventions aimed specifically at ameliorating the many adverse effects of extreme prematurity that lead to the poor neurocognitive outcomes we have described.

\section{ACKNOWLEDGMENTS}

The ELGAN Study Investigators are as follows: Janice Ware, Taryn
Coster, Brandi Henson, Rachel Wilson, Kirsten McGhee, Patricia Lee, Aimee Asgarian, and Anjali Sadhwani (Boston Children's Hospital, Boston, MA); Ellen Perrin, Emily Neger, Kathryn Mattern, Jenifer Walkowiak, and Susan Barron (Tufts Medical Center, Boston, MA); Jean Frazier, Lauren Venuti, Beth Powers, Ann Foley, Brian Dessureau, Molly Wood, and Jill Damon-Minow (University of Massachusetts Medical School, Worcester, MA); Richard Ehrenkranz, Jennifer Benjamin, Elaine Romano, Kathy Tsatsanis, Katarzyna Chawarska, Sophy Kim, Susan Dieterich, and Karen Bearrs (Yale University School of Medicine, New Haven, CT); T. Michael O'Shea, Nancy Peters, Patricia Brown, 
Emily Ansusinha, Ellen Waldrep, Jackie Friedman, Gail Hounshell, and Debbie Allred (Wake Forest University Baptist Medical Center, Winston-Salem, NC); Stephen C. Engelke, Nancy Darden-Saad, and Gary Stainback (University Health Systems of Eastern Carolina, Greenville, NC); Diane Warner, Janice Wereszczak, Janice Bernhardt, Joni McKeeman, and Echo Meyer (North Carolina Children's Hospital, Chapel Hill, NC); Steve Pastyrnak, Wendy Burdo-Hartman, Julie Rathbun, Sarah Nota, and Teri Crumb (Helen DeVos
Children's Hospital, Grand Rapids, MI); Madeleine Lenski, Deborah Weiland, and Megan Lloyd (Sparrow Hospital, Lansing, MI); Scott Hunter, Michael Msall, Rugile Ramoskaite, Suzanne Wiggins, Krissy Washington, Ryan Martin, Barbara Prendergast, and Megan Scott (University of Chicago Medical Center, Chicago, IL); and Judith Klarr, Beth Kring, Jennifer DeRidder, and Kelly Vogt (William Beaumont Hospital, Royal Oak, MI).

We thank the children and their families who participated in this study. We also acknowledge the contributions of the ELGAN Study Investigators.

Address correspondence to Robert M. Joseph, PhD, Department of Anatomy and Neurobiology, Boston University School of Medicine, 72 East Concord St, L-816, Boston, MA., 02118. E-mail: rmjoseph@bu.edu

PEDIATRICS (ISSN Numbers: Print, 0031-4005; Online, 1098-4275)

Copyright @ 2016 by the American Academy of Pediatrics

FINANCIAL DISCLOSURE: The authors have indicated they have no financial relationships relevant to this article to disclose.

FUNDING: This study was supported by grants from the National Institute of Neurologic Disorders and Stroke (5U01NS040069-05, 2R01NS040069-06A2) and the National Institute of Child Health and Human Development (5P30HD018655-28). Funded by the National Institutes of Health (NIH).

POTENTIAL CONFLICT OF INTEREST: The authors have indicated they have no potential conflicts of interest to disclose.

\section{REFERENCES}

1. Johnson S, Fawke J, Hennessy E, et al. Neurodevelopmental disability through 11 years of age in children born before 26 weeks of gestation. Pediatrics. 2009;124(2). Available at: www.pediatrics.org/cgi/content/full/ 124/2/e249

2. Hutchinson EA, De Luca CR, Doyle LW, Roberts G, Anderson PJ; Victorian Infant Collaborative Study Group. School-age outcomes of extremely preterm or extremely low birth weight children. Pediatrics. 2013;131(4). Available at: www.pediatrics.org/cgi/ content/full/131/4/e1053

3. Løhaugen GC, Gramstad A, Evensen $K A$, et al. Cognitive profile in young adults born preterm at very low birthweight. Dev Med Child Neurol. 2010;52(12):1133-1138

4. Lundequist $A, B o ̈ h m ~ B$, Lagercrantz $H$, Forssberg H, Smedler AC. Cognitive outcome varies in adolescents born preterm, depending on gestational age, intrauterine growth and neonatal complications. Acta Paediatr. 2015;104(3):292-299
5. Orchinik LJ, Taylor HG, Espy KA, et al. Cognitive outcomes for extremely preterm/extremely low birth weight children in kindergarten. J Int Neuropsychol Soc. 2011;17(6):1067-1079

6. Taylor HG, Klein N, Drotar D, Schluchter M, Hack M. Consequences and risks of $<1000$-g birth weight for neuropsychological skills, achievement, and adaptive functioning. J Dev Behav Pediatr. 2006;27 (6):459-469

7. Anderson PJ, De Luca CR, Hutchinson E, Spencer-Smith MM, Roberts G, Doyle LW; Victorian Infant Collaborative Study Group. Attention problems in a representative sample of extremely preterm/extremely low birth weight children. Dev Neuropsychol. 2011;36(1):57-73

8. Kulseng S, Jennekens-Schinkel A, Naess P, et al. Very-low-birthweight and term small-for-gestational-age adolescents: attention revisited. Acta Paediatr. 2006;95(2):224-230
9. Aarnoudse-Moens CS, Smidts DP, Oosterlaan J, Duivenvoorden HJ, Weisglas-Kuperus N. Executive function in very preterm children at early school age. J Abnorm Child Psychol. 2009;37(7):981-993

10. Bayless S, Stevenson J. Executive functions in school-age children born very prematurely. Early Hum Dev. 2007;83(4):247-254

11. Burnett AC, Scratch SE, Anderson PJ. Executive function outcome in preterm adolescents. Early Hum Dev. 2013;89(4):215-220

12. Kallankari $H$, Kaukola T, Olsén $P$, Ojaniemi M, Hallman M. Very preterm birth and foetal growth restriction are associated with specific cognitive deficits in children attending mainstream school. Acta Paediatr. 2015;104(1):84-90

13. Luu TM, Ment L, Allan W, Schneider $\mathrm{K}$, Vohr BR. Executive and memory function in adolescents born very preterm. Pediatrics. 2011;127(3). Available at: www.pediatrics.org/cgi/ content/full/127/3/e639 
14. Marlow N, Hennessy EM, Bracewell MA, Wolke D. Motor and executive function at 6 years of age after extremely preterm birth. Pediatrics. 2007;120(4):793-804

15. Anderson P, Doyle LW; Victorian Infant Collaborative Study Group. Neurobehavioral outcomes of schoolage children born extremely low birth weight or very preterm in the 1990s. JAMA. 2003;289(24):3264-3272

16. Mulder $\mathrm{H}$, Pitchford NJ, Marlow N. Processing speed and working memory underlie academic attainment in very preterm children. Arch Dis Child Fetal Neonatal Ed. 2010;95(4):F267-F272

17. Rose SA, Feldman JF. Memory and processing speed in preterm children at eleven years: a comparison with fullterms. Child Dev. 1996;67 (5):2005-2021

18. Johnson S, Hennessy E, Smith R, Trikic R, Wolke D, Marlow N. Academic attainment and special educational needs in extremely preterm children at 11 years of age: the EPICure study. Arch Dis Child Fetal Neonatal Ed. 2009;94(4):F283-F289

19. Kovachy VN, Adams JN, Tamaresis JS, Feldman HM. Reading abilities in school-aged preterm children: a review and meta-analysis. Dev Med Child Neurol. 2015;57 (5):410-419

20. Litt JS, Gerry Taylor H, Margevicius S, Schluchter M, Andreias L, Hack M. Academic achievement of adolescents born with extremely low birth weight. Acta Paediatr. 2012;101(12):1240-1245

21. Kerr-Wilson CO, Mackay DF, Smith GC, Pell JP. Meta-analysis of the association between preterm delivery and intelligence. J Public Health (Oxf). 2012;34(2):209-216

22. Linsell L, Malouf R, Morris J, Kurinczuk JJ, Marlow N. Prognostic factors for poor cognitive development in children born very preterm or with very low birth weight: a systematic review. JAMA Pediatr. 2015;169(12):1162-1172

23. Taylor HG. Multiple risks for long-term cognitive impairments following preterm birth. Acta Paediatr. 2015;104(3):218-220

24. Stoll BJ, Hansen NI, Bell EF, et al; Eunice Kennedy Shriver National Institute of Child Health and Human Development Neonatal Research Network. Trends in care practices, morbidity, and mortality of extremely preterm neonates, 19932012. JAMA. 2015;314(10):1039-1051

25. Kaufman AS, Kaufman NL. Kaufman Brief Intelligence Test. 2nd Edition. San Antonio, TX: Pearson Education; 2004

26. O'Shea TM, Allred EN, Dammann 0, et al; ELGAN Study Investigators. The ELGAN study of the brain and related disorders in extremely low gestational age newborns. Early Hum Dev. 2009;85(11):719-725

27. Palisano RJ, Hanna SE, Rosenbaum PL, et al. Validation of a model of gross motor function for children with cerebral palsy. Phys Ther. 2000;80(10):974-985

28. Elliott CD. Differential Ability Scales-II (DAS-II). San Antonio, TX; Pearson Education; 2007

29. Joseph RM, Fein D. The significance of IQ and differential cognitive abilities for understanding ASD. In: Fein , ed. The Neuropsychology of Autism. Oxford, United Kingdom: 0xford University Press; 2011:281-294

30. Carrow-Woolfolk E. OWLS, Oral and Written Language Scales. San Antonio, TX: Pearson Education; 1995

31. Korkman M, Kirk U, Kemp S. NEPSY-II: Clinical and Interpretive Manual. San Antonio, TX: The Psychological Corporation; 2007

32. Wechsler D. The Wechsler Individual Achievement Test-III. San Antonio, TX: Pearson Assessment; 2009

33. Roberts G, Anderson PJ, Doyle LW; Victorian Infant Collaborative Study Group. Neurosensory disabilities at school age in geographic cohorts of extremely low birth weight children born between the 1970s and the 1990s J Pediatr. 2009;154(6):829-834, e821

34. Anderson PJ. Neuropsychological outcomes of children born very preterm. Semin Fetal Neonatal Med. 2014;19(2):90-96

35. Leviton A, Blair E, Dammann 0, Allred $E$. The wealth of information conveyed by gestational age. J Pediatr. 2005;146(1):123-127

36. Sanders EJ, Harvey S. Peptide hormones as developmental growth and differentiation factors. Dev Dyn. 2008;237 (6):1537-1552

37. Back SA. Brain injury in the preterm infant: new horizons for pathogenesis and prevention. Pediatr Neurol. 2015;53(3):185-192

38. Haynes RL, Borenstein NS, Desilva $\mathrm{TM}$, et al. Axonal development in the cerebral white matter of the human fetus and infant. J Comp Neurol. 2005;484(2):156-167

39. Kostović I, Jovanov-Milošević N. The development of cerebral connections during the first 20-45 weeks' gestation. Semin Fetal Neonatal Med. 2006;11(6):415-22

40. Leviton A, Gressens P. Neuronal damage accompanies perinatal whitematter damage. Trends Neurosci. 2007;30(9):473-478

41. Rees S, Harding R, Walker D. The biological basis of injury and neuroprotection in the fetal and neonatal brain. Int J Dev Neurosci. 2011;29(6):551-563

42. Dammann 0, Leviton A. Brain damage in preterm newborns: might enhancement of developmentally regulated endogenous protection open a door for prevention? Pediatrics. 1999;104(3 pt 1):541-550

43. Ball G, Boardman JP, Rueckert D, et al. The effect of preterm birth on thalamic and cortical development. Cereb Cortex. 2012;22(5):1016-1024

44. Nosarti C, Giouroukou E, Healy E, et al Grey and white matter distribution in very preterm adolescents mediates neurodevelopmental outcome. Brain. 2008;131 (pt 1):205-217

45. Pandit AS, Robinson E, Aljabar P, et al. Whole-brain mapping of structural connectivity in infants reveals altered connection strength associated with growth and preterm birth. Cereb Cortex. 2014;24(9):2324-2333

46. Ball G, Srinivasan L, Aljabar P, et al. Development of cortical microstructure in the preterm human brain. Proc Natl Acad Sci USA. 2013;110(23):9541-9546

47. Thompson DK, Lee KJ, Egan GF, et al. Regional white matter microstructure in very preterm infants: predictors and 7 year outcomes. Cortex. 2014 Mar;52:60-74

48. Young JM, Powell TL, Morgan BR, et al. Deep grey matter growth predicts neurodevelopmental outcomes in very preterm children. Neuroimage. 2015 May;111:360-368 